LA INVENCIÓN DEL PATRIMONIO NATURAL EN ESPAÑA. POLÍTICA, ACADEMIA, ACTIVISMO Y COMUNICACIÓN /

THE INVENTION OF NATURAL HERITAGE IN SPAIN. POLITICS, ACADEMY, ACTIVISM AND COMMUNICATION

\section{LA NATURALEZA NO EXISTE: CONSERVACIONISMOS Y RELACIONES INTERNACIONALES EN DOÑANA}

\author{
Lino Camprubí \\ Max Planck Institute for the History of Science \\ Icamprubi@mpiwg-berlin.mpg.de
}

Cómo citar este artículo/Citation: Camprubí, L. (2016). La Naturaleza no existe: conservacionismos y relaciones internacionales en Doñana. Arbor, 192 (781): a344. doi: http:// dx.doi.org/10.3989/arbor.2016.781n5002

Recibido: 25 febrero 2015. Aceptado: 09 octubre 2015.

RESUMEN: Tras descartar el acercamiento metodológico a la historia de Doñana como un paso hacia la "conservación de la Naturaleza" con mayúscula, este artículo sitúa la historia del Parque en los contextos políticos, personales y científicos que lo hicieron posible. Estos contextos nos colocan en la escala internacional del desmantelamiento del imperio británico y de la transformación de la ornitología y la ecología como disciplinas. Las rutas migratorias de las aves de Doñana contribuyeron a la dimensión internacional en la que se fraguó el acuerdo entre el World Wildlife Fund (WWF) y el Consejo Superior de Investigaciones Científicas (CSIC) que llevó a la inauguración de la Reserva Biológica de Doñana en 1965. La posterior creación del Parque abrió la puerta a nuevos desencuentros entre diversos modos de entender el conservacionismo y entre diferentes categorizaciones científicas del territorio de Doñana. La resolución de estos conflictos dependió de fuerzas y alianzas, lo que permite concluir afinando el argumento metodológico de partida.

PALABRAS CLAVE: Doñana; World Wildlife Fund; Valverde; Huxley; Franco; ecología; conservación; relaciones internacionales; Parques Nacionales.

\section{NATURE DOES NOT EXIST: CONSERVATIONISMS AND INTERNATIONAL RELATIONS IN DOÑANA}

Copyright: (C) 2016 CSIC. Este es un artículo de acceso abierto distribuido bajo los términos de la licencia Creative Commons Attribution (CC BY) España 3.0.

ABSTRACT: The paper starts by discarding the methodological approach to the history of Natural Parks that sees them as steps towards the "conservation of Nature" - with a capital N. Rather, it situates the history of Doñana within its political, personal and scientific contexts. These contexts bring us to an international scale marked by the decolonization of the British Empire and the transformation of ornithology and ecology as disciplines. Bird migratory routes contributed to the Park's international dimension, in which context the agreement between the World Wildlife Fund (WWF) and the Consejo Superior de Investigaciones Cientificas $(C S I C)$ took place. Creation of the Park opened the door to new conflicts among diverging ways of understanding conservation and different scientific categorizations of Doñana's territory. The resolution of these conflicts depended on strengths and alliances, which allows us to conclude by refining our methodological starting point.

KEYWORDS: Doñana; World Wildlife Fund; Valverde; Huxley; Franco; ecology; conservation; international relations; Natural Parks. 


\section{INTRODUCCIÓN}

El Parque Nacional de Doñana constituye uno de los paisajes más llamativos del sur de España. Su relativo aislamiento histórico y su riqueza faunística han hecho que dentro y fuera de nuestras fronteras se hable de Doñana como el "último paraje salvaje europeo." El biólogo Francisco Bernis, uno de los hacedores de la protección de Doñana, recordaba su primera visita en 1952: "creo que aquel día me asomé por primera vez a la Naturaleza con mayúscula" (Fernández y Pradas Regel, 2000, p. 58). Desde este punto de vista, el de quien encuentra en Doñana la Naturaleza con mayúscula, la historia de su preservación frente a alternativas en competencia por el uso de ese territorio representa el triunfo de la conservación de la naturaleza. Un triunfo, si no inevitable, sí evidente en su perentoriedad y significado tanto como para sus autores como para los historiadores encargados de recoger su legado. Se hablará de una lucha por parte de los amantes de la naturaleza contra los obstáculos que en el camino iban poniendo los que estaban dispuestos a destruirla. Una lucha diáfana aunque de resultado incierto, lo que acentúa el heroísmo de los implicados (Delibes de Castro, 2006; Garrido, 2007; Molina, 2011).

Y sin embargo, ¿por qué Doñana y no otros parajes naturales españoles aún más ricos en biodiversidad? ${ }^{1}$ Esta simple pregunta ya nos obliga a descender a aspectos peculiares de Doñana como encrucijada geográfico-histórica en la que se dieron cita una variedad de líneas históricas sin las cuales su conservación no hubiera sido posible. Por ejemplo, la historia de Doñana está ligada al atractivo de la ornitología para los conservacionistas de la segunda mitad del siglo XX, lo que lleva a introducir cuestiones disciplinares $y$ aun estéticas a la hora de dar cuenta de la historia de su conservación. Cabe recordar, además, que Doñana supuso una excepción en la historia de los Parques españoles y su historia no es en absoluto representativa de los esfuerzos conservacionistas del franquismo. De entre los Parques inaugurados en las décadas centrales del siglo XX, de los que habla Santos Casado en este mismo número ${ }^{2}$, Doñana fue el primero no paisajístico-alpino, sino orientado a la protección de la fauna, el primero en combinar desde sus orígenes investigación con protección, y aquél en cuya gestación tuvieron mayor preponderancia las dimensiones internacionales (Fernández y Pradas Regel, 2000). Estas tres peculiaridades están conectadas entre sí, como quedará claro a lo largo de este artículo. Pero por ahora baste señalar que, ante este telón de fondo, la conservación de Doñana no era ni mucho menos evidente.
Podemos incluso hacer una pregunta más general y más directa, ¿qué significa eso de la "conservación de la naturaleza" y cómo ha cambiado este significado a lo largo del tiempo? Por lo que respecta al conservacionismo, lo cierto es que en Doñana se dieron cita diversas tradiciones de conservacionismos, en concreto las que enfatizaban la investigación científica y las que se decantaban por el recreo. Entre estas hubo choques e incompatibilidades cuya resolución dependió de factores externos a la disputa, como las relaciones internacionales y las fuentes de financiación. Por lo que a la naturaleza se refiere, la univocidad de esta idea se ve comprometida por la variedad de disciplinas científicas que operaban en Doñana y su entorno y que interpretaban el territorio de modos a veces incompatibles. Estas incompatibilidades entre científicos de diferentes disciplinas implicaban distintos planes de transformación. Ornitólogos, ecólogos, ingenieros forestales, ingenieros de caminos, genetistas del arroz, edafólogos, geólogos...todos operaban con distintas naturalezas y tenían algo que decir sobre Doñana y su futuro. De nuevo, cuál de estas visiones fuera la victoriosa no dependía de un árbitro neutral (la Naturaleza), sino de cuál de los contendientes tuviera más fuerza, por ejemplo, más contactos en los círculos con poder financiero o de toma de decisión.

Por tanto, este artículo no toma a la Naturaleza como punto de partida ni llegada en la historia de Doñana. Más bien, en la línea de trabajos recientes sobre Parques Naturales de otros países, trata de reconstruir esta historia preguntando por los sujetos que la hicieron posible y su inscripción en contextos geopolíticos, ideológicos y científicos (Mels, 1999; Spence, 1999; Gissibl, Höhler y Kupper, 2012). La historia de Doñana no es solamente el resultado de una creciente preocupación por la naturaleza, sino que es uno de los hitos que permite entender la transformación científica e ideológica de la idea misma de naturaleza en contextos precisos de diversidad disciplinar y política internacional.

\section{CAZADORES DE IMÁGENES: EL WWF Y LA CONS- TRUCCIÓN DE LO SALVAJE}

Tras la Segunda Guerra Mundial, tanto el conservacionismo de la naturaleza como la naturaleza misma tuvieron que redefinirse. La evocación nacionalista de parajes naturales de trascendencia histórica y de un suelo patrio que encarnaría los valores de la raza había sido parte integral de los programas de conservación de la primera mitad del siglo XX en Estados Unidos, Alemania y España, entre otros países; y, como en 
otras ocasiones, este movimiento nacionalista había tenido un alcance internacional (Blackbourne, 2006; Casado, 2010; Harper y White, 2012; Tyrrell, 2012). Pero este enfoque ya no bastaba en un contexto de Guerra Fría y descolonización en el que Estados Unidos adquiría nuevas responsabilidades como imperio triunfante. Ahora la conservación se fomentaba a nivel internacional como parte de un promesa de prosperidad general por parte del capitalismo norteamericano al resto del mundo, en especial a aquellos países con más riesgo de caer en la órbita soviética (Mitmann, 1999, p. 180ss; Macekura, 2011). Simultáneamente, los programas de investigación desarrollados por los militares de la era nuclear daban forma a nuevas ideas de interdependencia global y a un nuevo lenguaje apocalíptico que pronto sería integrado por discursos conservacionistas (Edwards, 2010; Hamblin, 2013; Turchetti y Roberts, 2014). La ecología se consolidaba como ciencia y trataba de ir más allá del ecosistema local hacia una escala global en la que emergían el medio ambiente (con artículo definido masculino singular) y la biosfera (aunque el concepto es, como se sabe, anterior) como entidades dotadas de unicidad y en nombre de las cuales se podían realizar análisis y predicciones a nivel planetario, tanto malthusianos y económicos como climáticos y ecológicos (Höhler, 2007; Mitchell, 2011; Lawrence, 2015).

El papel del Reino Unido en los procesos de cambio geopolítico tras la Segunda Guerra Mundial ha sido bien estudiado. Su lugar en el concierto internacional había pasado a un segundo plano y, sin embargo, los oficiales de su imperio fueron determinantes para instituciones clave del nuevo orden mundial tales como la Organización de las Naciones Unidas (ONU) y su hijuela la UNESCO, dedicada a la Educación, la Ciencia y la Cultura (Mazower, 2008). El primer director general de esta última, el biólogo inglés de familia de científicos y escritores egregios Julian Huxley, esperaba que la UNESCO continuase la labor civilizatoria iniciada por el imperio británico (Sluga, 2010). Su visión eugenésica y progresista otorgaba al recreo en la naturaleza un valor cultural y moralizante además de económico. Como fundador del think tank londinense Political and Economic Planning promovió una visión tecnocrática en el que la labor civilizatoria británica habría de abarcar ahora a la naturaleza. Probablemente inspirado por su experiencia como gerente de zoológico, Huxley sostenía que las ciencias y tecnologías de la era nuclear ponían al hombre a cargo de guiar la evolución e incluso los cambios geológicos, una suerte de precedente optimista de lo que algunos geólogos actuales llaman la era del Antropoceno (Waters y van Helden, 1992; Deese, 2010).
A lo largo de las décadas 50 y 60, a medida que Gran Bretaña se retiraba de sus territorios en Oriente y África, una de las prioridades de Huxley y su entorno fue la de evitar el desmoche de las instituciones conservacionistas que el imperio había ido implantando en las primeras décadas del siglo XX, las más de las veces como instrumentos para impedir el acceso de los nativos a la gran fauna que permitía a los ingleses practicar el que todavía era el sport por excelencia: la caza (Anderson y Groves, 1987; Mackenzie, 1988, pp. 261-294; Gissibl, Höhler y Kupper, 2012; Adam, 2014, pp. 33-39). La preocupación por los efectos de la descolonización sobre la fauna africana fue una de las razones que llevaron a la creación del World Wildlife Fund (WWF) en 1961 y a los posteriores acuerdos de esta institución con líderes postcoloniales de la talla del General Mobutu (Schwarzenbach, 2011, p. 99).

En este contexto, en 1948 Huxley auspició desde la UNESCO la Unión Internacional para la Conservación de la Naturaleza (UICN) en oposición a otros programas de la ONU de corte más utilitarista que hablaban de recursos naturales solamente en términos de su aprovechamiento económico, que en todo caso no eran ajenos a la UICN (Schwarzenbach, 2011, pp. 3638; Wöbse, 2012). Uno de los encargados por Huxley para organizar la UICN fue uno de los cofundadores y principal ideólogo del grupo Political and Economic Planning, el historiador, autor de varios libros populares de ornitología, y alto administrativo de la corona Max Nicholson (Huxley, 1973, pp. 210-211). Irlandés de padres ingleses, Nicholson había fundado el British Trust for Ornithology y trabajaba desde 1943 en el British Nature Conservancy, desde donde había organizado la reordenación de los Parques Naturales en el Reino Unido con vistas a la compatibilidad entre investigación científica, aprovechamiento económico y recreación (Allen, 1976/1994, pp. 227-244; Schleper, 2016). A medida que la UICN se perfilaba como una institución científica de referencia en el estudio de problemas ecológicos globales, una segunda razón que motivó la creación del WWF fue la necesidad de dotar a la UICN de medios económicos.

Huxley y Nicholson se encontraron en Doñana en 1957 para formar parte de una expedición ornitológica con tintes botánicos (envío de ejemplares a los jardines de Kew), ecológicos (estudio de distribución y ecosistemas) y etológicos (estudio de conductas nidificadoras y cantoras) (Huxley, 1973, pp. 181-184). Allí se reunieron con otros ingleses procedentes de la honorable estirpe de los gentlemen naturalistas y destacados en sus respectivas carreras militares, artís- 
Figura 1. Huxley y Nicholson en Doñana en 1966

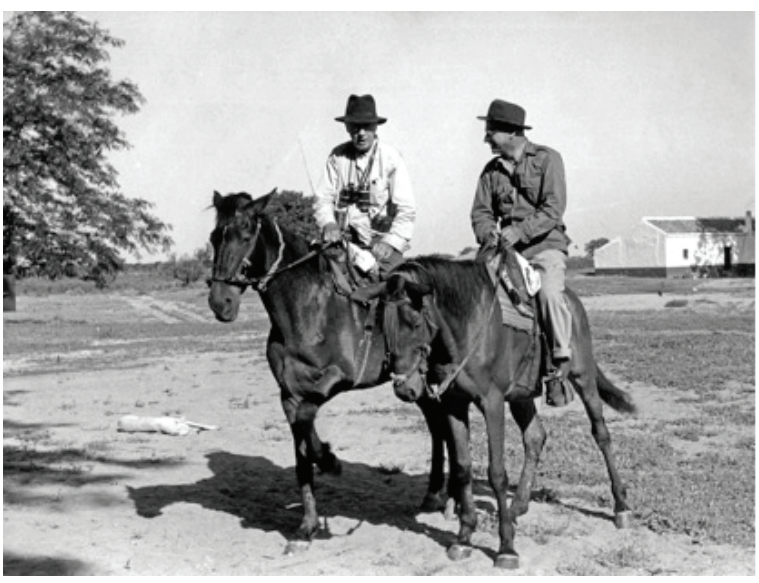

Fuente: Banco de imágenes de Estación Biológica de Doñana-CSIC.

ticas o empresariales (Moss, 2013, pp. 150-222). Era un tiempo en que las dos corrientes de la ornitología, la biologicista-ecóloga y la de los aficionados, aún no se habían separado del todo (Barrow, 2011; de Bont, 2011) $)^{3}$. A todos los había reunido allí Guy Mountfort, un rico publicista y autor del exitoso libro Field Guide to the Birds of Britain and Europe, que había publicado en 1954 junto con otros dos miembros integrantes de la expedición: el americano Roger T. Peterson, entre los mejores pintores de aves del momento, y el ornitólogo inglés Phil Hollom, experto en distribución geográfica de especies. Mountfort ya había organizado dos expediciones previas a Doñana en 1952 y 1956 $y$, entre otras personas, al menos a una de ellas acudieron las siguientes figuras relevantes para esta historia: el vizconde Alambrooke, principal asesor militar de Wiston Churchill durante la Segunda Guerra Mundial y gran aficionado a la caza y el cine; Erik Hosking, el más conocido profesional de la fotografía de aves de la época; y James Ferguson-Lees, joven ornitólogo y asistente de Nicholson en la edición de la revista del British Trust for Ornithology, British Birds ${ }^{4}$.

La expedición de 1957 llevó a Nicholson a afirmar años más tarde que "el reto de Doñana contribuyó más que cualquier otro factor a la fundación del World Wildlife Fund en $1961 .{ }^{\prime \prime}$ La tesis ha sido varias veces defendida desde España, aunque si tenemos en cuenta que las relaciones personales entre los expedicionarios interesados en Doñana se fraguaron en tradiciones y contextos distintos a las marismas pierde toda la fuerza de su sentido. Será más ajustado decir que Doñana fue uno de los nudos de un tejido mucho más amplio. En cualquier caso, lo cierto es que varios
Figura 2. Miembros integrantes de la expedición de 1957

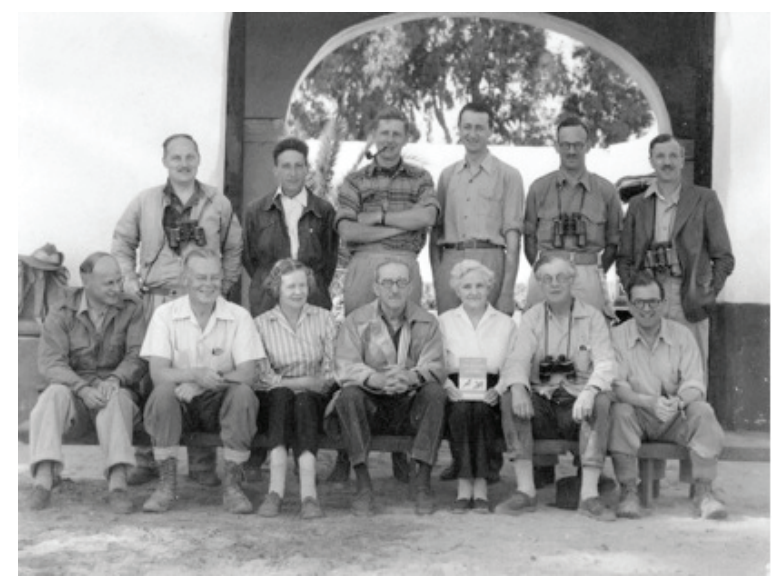

Fuente: Banco de imágenes de Estación Biológica de Doñana-CSIC.

de los expedicionarios del 57 fueron los principales impulsores del WWF y que la protección de Doñana fue el proyecto al que esta institución destinó más fondos en su primera década.

En su historia del WWF, Alexis Schwarzenbach subraya el origen colonial del Fondo y llama la atención sobre la "sorpresa" de que el proyecto económicamente más importante en los primeros años de una organización creada para frenar una temida hecatombe africana fueran las marismas de Doñana (Schwarzenbach, 2011, pp. 95-98). La sorpresa puede mitigarse teniendo en cuenta que los ingleses del WWF miraban a Doñana como un puente entre Europa y África, cuando no como una extensión de África misma (López Ontiveros, 2006). En lo primero jugaba un papel fundamental la migración de las aves, que como en Gibraltar, cruzaban de un continente a otro con el cambio de estaciones. En lo segundo influía la tradición. Mountfort y el resto habían leído sobre Doñana en los libros de compatriotas suyos que visitaron Doñana en el siglo XIX con "rifle, caña y pistola" (Chapman y Buck, 1893). Con excepciones como la de Alambrooke, es cierto que los expedicionarios ingleses de 1957 habían "cambiado la escopeta por la cámara fotográfica" (Mountfort, 1958/1994). Pero, como otros cazadores de imágenes de la época, no habían modificado la identidad masculina del explorador inglés, el caballero que se enfrenta a una naturaleza exótica (Ryan, 1997, pp. 99-139; Matless, 1998; Dunaway, 2000; Brower, 2011). Tampoco se habían alejado excesivamente de la representación romantizada que del sur de España habían dibujado los ingleses decimonónicos, vinculando Andalucía a su pasado 
islámico y creyendo ver en ella un rincón más oriental y africano que europeo: "Andalucía, más africana que África" (Chapmann y Buck, 1893, p.1).

Pero Doñana además ofrecía la ventaja de la estabilidad sobre los convulsos países africanos en pleno proceso de descolonización. De hecho, el propio Schwarzenbach documenta que, a pesar del interés africanista, la mayor parte del presupuesto de la primera década del WWF y sus diferentes ramas nacionales fue a parar a proyectos en Europa y Estados Unidos, a menudo por simple posibilismo. A pesar de las malas relaciones diplomáticas entre Gran Bretaña y el régimen de Franco, lo cierto es que existían vínculos históricos y personales que hacían posible la colaboración. Esto es evidente en la propia estructura de la expedición del 57. Mountfort organizó la expedición por invitación de uno de los propietarios de las tres fincas en las que estaba dividido el Coto, Mauricio González-Gordon. Este rico heredero de una de las mayores bodegas jerezanas era hijo de madre inglesa y padre español, y por tanto bilingüe y capaz de mediar entre estilos y expectativas diferentes, como lo atestiguan sus traducciones de libros de ornitología ingleses. Gran aficionado a la caza y a la ornitología, en 1952 invitó a Bernis a realizar en su finca el primer proyecto de anillamiento de aves en Doñana. Para ello contaron con la colaboración del entonces joven y prometedor biólogo José Antonio Valverde, ya bregado en la exploración colonial española del Sáhara Occidental, sobre la que versaron sus primeros escritos sobre ecología de aves. En 1954, los tres participaron en la fundación de la Sociedad Española de Ornitología, desde sus inicios coordinada con el British Ornithologist Union, mucho más firmemente establecida (Fernández, 2004; Boardman, 2006, pp. 120-125). Ese mismo año, González-Gordon y los otros dos propietarios invitaron a Franco a cazar al coto y, con ayuda de Bernis, redactaron una carta por la cual pedían al General una moratoria en los proyectos estatales de plantación de eucaliptos en la zona, que amenazaban con transformar drásticamente el paisaje local. La carta, que al menos en parte logró el objetivo propuesto, no invocaba a la Naturaleza con mayúscula que Bernis dijo años más tarde haber encontrado en su primera visita a Doñana, sino que hablaba de conservación en términos de naturaleza patria y de "paraíso cinegético y zoológico de Europa” (Duque, 1977/2004).

González Gordon, Bernis y Valverde formaron parte de la expedición del 57 en calidad de expertos locales. En años posteriores se resintieron de lo que consideraban la ocultación sistemática por parte de los ingleses de la labor de los españoles, recordando por ejemplo que la primera relación de las aves de Doñana fue la escrita en 1852 por Antonio Machado y Núñez, abuelo del poeta. Según Valverde, cuando él y Bernis preguntaron por qué no se citaban sus propios importantes estudios de anillamiento de 1953, Mountfort respondió que "fue por no quitarle salvajismo al Coto" (Valverde, 2004, p. 27). Doñana no era pues una terra incognita.

Pero tampoco era una terra nullius. Los biólogos profesionales y ornitólogos aficionados de la expedición del 57 contaron con la imprescindible ayuda de los guardas privados del Coto, cuyo conocimiento de la vegetación y fauna locales se había fraguado durante generaciones. $Y$ este conocimiento no era meramente pasivo. Durante siglos, los guardas habían sido los encargados de que Doñana no fuese un paraje salvaje, por ejemplo limpiando o quemando sus bosques, introduciendo nuevas especies vegetales y animales y exterminado otras consideradas malignas (Ojeda Rivera, 1985; González Gordon, 2000; Morenés y Mariátegui, 2005; García Novo, Martín y Toja, 2007). Un año después de la expedición, Mountfort publicó un libro sobre Doñana con fotografías de Hosking Ilamando a su conservación. En la tradición del Wild Spain de Chapmann y Buck, ya el título evocaba la idea de una naturaleza virgen y con mayúscula: Portrait of a Wilderness. El colonialismo europeo había considerado a África como una tierra de nadie, un gran vacío esperando la civilización y explotación (Blackbourne, 2006; Tylley, 2011). Las constantes menciones a Doñana como una tierra inhabitada e inmaculada reforzaban en este sentido su africanización a la vez que contribuían a crear una idea de naturaleza prístina.

"Cuando vi por primera vez el coto, era ciertamente un lugar inalterado" escribió Mountfort en la edición española de Portrait of a Wilderness (Mountfort, 1958/1994, p. XI). Pero tanto él como Nicholson sabían que "en contraste con la opinión común de que Doñana representa un área virgen poco influida por el hombre, la realidad es que estamos tratando con ecosistemas... profundamente modificados por actividades humanas desde la Antigüedad." ${ }^{6}$ Sin embargo, consideraban que para fomentar su conservación era mejor obviar esa historia y crear, en sus propias palabras, una "mística" que, como veremos más adelante, resultó esconder algunos peligros para sus propios objetivos (Duque, 1977/2004) 7 .

En este proceso de construcción de lo salvaje, la fotografía y el cine tuvieron un papel importante. La presentación del libro de Mountfort en Inglaterra se 
Figura 3. Fotografía de Hosking de un águila alimentando a su cría

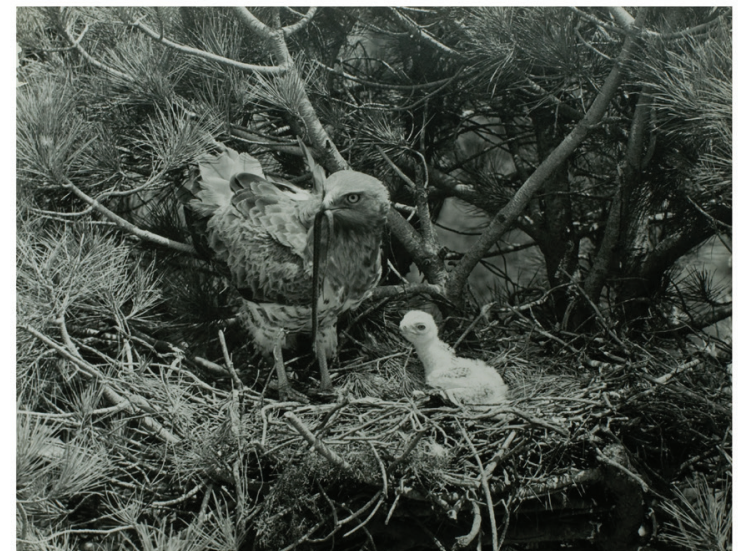

Fuente: Banco de imágenes de Estación Biológica de Doñana-CSIC.

acompañó del estreno de la película Wild Spain, grabada por Alambrooke en Doñana - al estreno acudieron González-Gordon y el entonces todavía embajador español en Gran Bretaña, Miguel Primo de Rivera (Mountfort a Nicholson, 9 enero 1958, Archivo Nicholson Papers, en adelante NP). Como en otros casos bien conocidos por los historiadores, la fotografía animal requería de artificios para producir situaciones naturales, como la provisión de presas para los depredadores o la construcción de hides, tan importantes en la expedición del 57. Más esencialmente: para que la imagen del animal aparezca como real, la propia tecnología de la fotografía tiene que desaparecer (Mitmann, 1999, p. 208; Bueno, 2000; Brower, 2011). Estas tecnologías fueron empleadas para producir la idea de una Naturaleza con mayúscula que fue clave a la hora de movilizar los recursos necesarios para su conservación en los años posteriores ${ }^{8}$.

\section{SOBREVOLAR FRONTERAS: MODELOS CONSERVA- CIONISTAS Y DIPLOMACIA}

El lector que conozca la historia de la "expedición de los ingleses" de 1957 se habrá percatado de que hasta ahora no he mencionado a uno de sus integrantes más relevantes, el suizo Luc Hoffmann (1923-2016). Hoffmann era heredero de Hoffmann-La Roche, una de las mayores industrias químicas suizas, y dedicaba su tiempo y rentas al conocimiento y protección de aves migratorias. En 1947 compró una parte de las marismas de La Camarga, en la desembocadura del Ródano, e instaló allí la estación ornitológica Tour $d u$ Valat. La Camarga tenía estatuto de reserva y estaba a cargo de la Société d'Acclimatation francesa, que en aquellos años trataba de ocultar su raigambre colonial cambiando su nombre por el de Société Nationale de Protection de la Nature, e ingresando como miembro institucional de la UICN. Desde unos años atrás, La Société venía editando un boletín dedicado a defender la protección de aquel santuario ornitológico frente al cultivo de arroz en la zona y la desecación proyectada para ello. Con un argumento que se tornaría importante en Doñana, la rama francesa de la UICN insistía en que el problema no era solo francés sino europeo, dada la importancia de la región para diversas especies de aves migratorias (Wöbse, 2012).

En 1953, Hoffmann unió fuerzas con Mountfort, por entonces afincado en Francia, y Nicholson, que actuaba en representación de la UICN. Diseñaron un plan de protección de La Camarga consistente en la creación de una sociedad de donantes y un acuerdo con el Centre Nacional de la Recherche Scientifique y la Estación Biológica Tour du Valat dirigida por Hoffmann (Bressou, 1954). La fórmula de Reserva Biológica respondía a la tradición del conservacionismo suizo en la que se insertaba Hoffmann y que suele asociarse al nombre de Paul Sarassin y a los primeros años de la UICN: los Parques suizos no eran zonas de recreo, sino áreas cerradas al público y dedicadas a la investigación científica, en particular ecológica (Kupper, 2009; Kupper, 2012; Rumore, 2012; de Bont, 2015). En esta línea, los científicos que trabajaban en La Camarga hablaban del turismo como una invasión semejante a la del arroz y deseaban limitar en lo posible las visitas a la Reserva restringiéndolas a los estudios científicos ornitológicos (Tallon, 1954).

Gracias a este acuerdo, Tour du Valat supuso un cambio de perspectiva en el proteccionismo de las aves, pues fue de las primeras instancias en las que la protección no se dedicó a especies sino al hábitat en las que estas se reproducían y alimentaban (Wöbse, 2012). Esto hizo que la Reserva adquiriese rápido prestigio internacional y se constituyera en modelo de protección de humedales.

Las marismas de Doñana y las de La Camarga tenían mucho en común, incluida la amenaza que para ambas suponían los cultivos arroceros. Desde los años de la Guerra Civil, en los que el bando nacional había visto en las marismas del Guadalquivir una alternativa al arroz cultivado en territorio republicano, la zona se había convertido en uno de los cotos arroceros más importantes de España (González Arteaga, 2005). Los genetistas de la Estación Arrocera de Sueca, encargados de la producción y distribución de semillas junto con el Sindicato Nacional del Trigo y la Federación Sin- 
dical de Agricultores Arroceros de España, veían este territorio como una inmenso cultivo de arroz (Camprubí, 2014). Junto con los edafólogos e ingenieros del Instituto Nacional de Colonización, se esforzaron por cuantificar y controlar la naturaleza salina de la marisma y sus acuíferos subterráneos.

Las semejanzas entre Doñana y La Camarga se hicieron aún más evidentes en la estrategia seguida para su conservación frente a estos proyectos alternativos. Hoffmann y Nicholson tomaron como modelo su experiencia previa en Tour du Valat. Dado el prestigio de ésta, se esforzaron por hacer las semejanzas explícitas y reforzarlas señalando conexiones, estas últimas proporcionadas por las costumbres migratorias de las propias aves. Los primeros estudios de anillamientos de flamencos por parte de Hoffmann señalaban que una parte de los flamencos franceses pasaban temporadas en el Guadalquivir (Hoffmann, 1962). Enterado de los anillamientos de Valverde, de quien conocía sus trabajos de ecología de vertebrados en el Sáhara, Hoffmann le invitó a pasar una temporada en La Camarga en el año 1954. Tras la expedición del 57 el proyecto de hacer una Reserva Biológica como la de Tour du Valat se consolidó, y Nicholson también invitó a Valverde a conocer durante unos meses la Nature Conservancy (Valverde, 2004, p. 38).

Con el objetivo de llamar la atención sobre Doñana apoyados en el prestigio de La Camarga, Nicholson, Hoffmann y Valverde concertaron publicar en la revista British Birds una serie de artículos ilustrados por fotografías de Hosking y dedicados a comparar ambas marismas. El primero de los artículos, escrito por los expedicionarios Nicholson, Ferguson-Lees y Hollom, subrayaba las similitudes ecológicas de las dos marismas y los peligros que acechaban a sus frágiles ecosistemas. En el segundo, Hoffmann daba cuenta de la ecología de La Camarga. El tercero, escrito por Valverde y traducido por Nicholson al inglés, hacía lo propio con Doñana (Nicholson, Ferguson-Lees y Hollom, 1957; Hoffmann, 1958; Valverde, 1958). Una versión reducida del mismo había servido a Nicholson unos meses antes para redactar uno de los capítulos del libro de Mountfort sobre Doñana9. Estos artículos se acompañaron de una serie de estudios relacionando los incrementos de salinidad en Doñana con perturbaciones del comportamiento nidificador de los flamencos del Ródano ${ }^{10}$. Si los datos se confirmaban y si esta salinización se podía achacar a un origen antropológico, en particular a los diques construidos para los cultivos de arroz, la situación merecería ser considerada de emergencia por los aficionados a la observación de aves.
Figura 4. Aves acuáticas en La Camarga

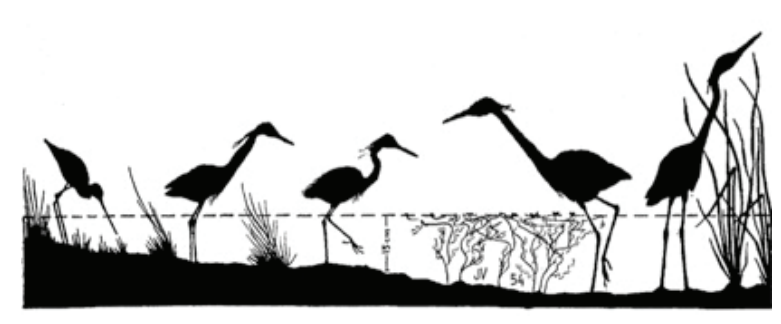

Fuente: Hoffmann (1958).

Esta estrategia bibliográfica era el primer paso de una campaña recaudatoria que desde el principio se concibió a escala internacional. Para ello Valverde contó con la ayuda de Peter Scott, uno de los pintores de fauna salvaje más cotizados del momento, incipiente estrella televisiva en el Reino Unido como presentador de programas de fauna salvaje, y gran aficionado a la caza de aves anátidas, para las que había instalado un zoológico en el sur de Inglaterra. Scott invitó a Valverde a presentar en dos importantes congresos el argumento de que los patos y ánades del norte de Europa necesitaban el cuartel de invierno de Doñana (Valverde, 2004, p. 61). Sin embargo, no fue hasta la creación del WWF en 1961 cuando se pudo dar forma creíble al proyecto de conservación de Doñana. Scott, la cabeza más visible del Fondo, declaraba contento una década más tarde que el WWF se había especializado en la protección de humedales, el hábitat de las especies que él mismo prefería (Schwarzenbach, 2011, p. 98).

Scott, junto con Nicholson, Hoffmann y otros pocos colaboradores, impulsaron el WWF con la intención explícita de recaudar dinero de empresarios y aristócratas acaudalados y amantes de los animales, y Doñana figura entre sus primeros proyectos. Siguiendo el modelo de La Camarga, se trataba de comprar tierras de González-Gordon y otros propietarios y, mediante un acuerdo con el Consejo Nacional de Investigaciones Científicas (CSIC), establecer una Reserva Biológica.

El contacto con el CSIC se estableció por la relación personal de Valverde con su secretario general, José María Albareda. Este químico y edafólogo fue uno de los artífices del establecimiento del sistema de investigación del primer franquismo, enfocado a la industrialización de la economía política. Fue también uno de los primeros miembros del Opus Dei y había inspirado pasajes de la obra Camino de José María Escrivá de Balaguer, en especial aquellos que apuntaban al estudio científico, considerado por Albareda y otros pieza fundamental del "concepto cristiano de 
la autarquía" (Camprubí, 2014). La piedad católica y la teoría evolutiva, sin embargo, eran incompatibles para Albareda, del que Valverde escribió que "pocos debieron de sufrir el dilema entre ciencia y obediencia tan agudamente como Don José María Albareda" (Valverde, 2003). Su interés por el incremento de la producción agrícola e industrial y su desapego por las ciencias evolucionistas no parecen hacer de Albareda un candidato ideal para unirse a la causa de los ecólogos ingleses. Y sin embargo, y redundando en la pluralidad de intereses conservacionistas implicados en Doñana, Albareda veía allí no solamente la oportunidad de preservar un paisaje emblemático, sino también la de establecer vínculos entre el CSIC y una institución como el $W W F$, que contaba con el beneplácito de líderes internacionales ante los cuales la ciencia española aumentaría su mermado prestigio (Valverde, 2004).

La colaboración estrecha entre Valverde y Albareda permitió iniciar las negociaciones para un acuerdo entre el CSIC y el WWF, que aun así se retrasó por numerosos obstáculos económicos, burocráticos y jurídicos que han sido suficientemente estudiados (Duque, 1977/2004). Es bien conocida la anécdota según la cual Valverde fue el autor de los dos polos del intercambio epistolar que mantuvieron Franco y el presidente del WWF, el Príncipe Bernardo de Holanda. La situación expresa muy bien la diversidad de agentes involucrados en la historia de la conservación de Doñana así como el papel diplomático que los científicos asumían para desarrollar sus proyectos a escala internacional (Doel, 1997). En 1965, el WWF aportó 22 millones de pesetas y el CSIC, 18 para la compra de unas 6.700 hectáreas en Doñana en las que el CSIC declaró una Estación Biológica dirigida por Valverde. Posteriores compras en los próximos años hicieron a Doñana la principal destinataria de los fondos del WWF, aunque a mediados de 1970 la aportación del Gobierno español ya superaba a la del WWF.

El dinero del WWF provenía en su mayor parte de aportaciones individuales. Los Ilamamientos a estas aportaciones dependían en parte de la organización a nivel internacional, pero sobre todo de sus filiales nacionales, y para Doñana fueron especialmente relevantes los donantes ingleses y suizos, lo cual no es de extrañar dada la procedencia de los expedicionarios y creadores del WWF. Más sorprendente a primera vista pueden parecer las abultadas contribuciones holandesas, danesas y suecas ${ }^{11}$. Sin embargo, una vez más las costumbres migratorias de las aves ayudan a solucionar el misterio. En 1966, una campaña del WWF-Suecia
Figura 5. Valverde ante la placa conmemorativa de la Estación Biológica de Doñana

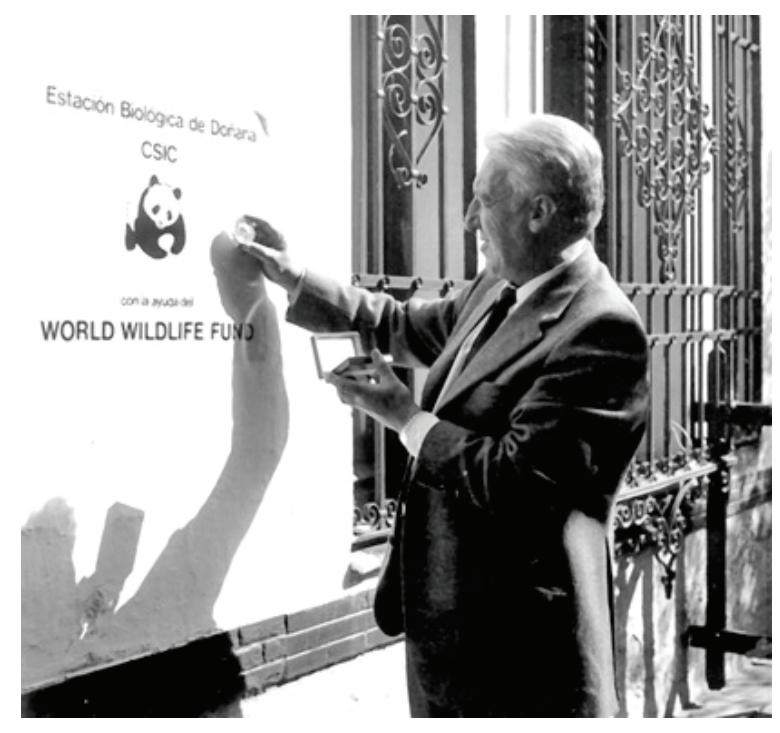

Fuente: Banco de imágenes de Estación Biológica de Doñana-CSIC.

para recaudar fondos para adquirir nuevos terrenos en las marismas hablaba de la "hibernación de nuestras aves de paso" y dos años después el WWF-Holanda hablaba de "nuestras aves migratorias holandesas." ${ }^{12}$

Los primeros tratados internacionales de protección de fauna y de aves planteaban la doble paradoja de que declarar protegida a una especie migratoria significaba en cierta medida sujetarla a las leyes nacionales, y por tanto apropiársela para la soberanía nacional, pero a la vez el único modo de hacer la protección efectiva era establecer acuerdos con otros países soberanos relevantes (Cioc, 2009; Adam, 2014). Como en esos otros casos, la naturaleza de Doñana era alternativamente nacional y transnacional dependiendo del contexto jurídico, científico y propagandístico.

\section{¿PARA QUÉ SIRVE UN PARQUE NACIONAL?}

En 1969, cuatro años después de la creación de la Reserva Biológica de Doñana, el decreto que declaraba a Doñana Parque Nacional lo ofrecía "en beneficio del pueblo español y como generosa aportación de España al Año Internacional de la Conservación de la Naturaleza y sus Recursos" (Decreto 2412/1969). El Año Internacional era una iniciativa auspiciada por la UICN con colaboración del WWF y del International Biological Program (IBP), sobre el que volveré más abajo. Ese mismo año de 1969 Hoffmann, Valverde y Félix Rodríguez de la Fuente, entre otros, habían lanzado Adena, la rama española del WWF con presidencia del enton- 
ces Príncipe Juan Carlos y dedicada en un principio a encauzar las crecientes aportaciones individuales que se hacían desde dentro de España a la Reserva y que fueron clave en el establecimiento de los primeros laboratorios en Doñana ${ }^{13}$. Desde esta nueva posición política, y a través de reuniones personales con Franco y sus ministros, los creadores de Adena habían instado a la creación del Parque como medida necesaria para defender la Reserva de intereses más poderosos, en especial quienes desde el Ministerio de Agricultura y el de Obras Públicas presionaban para extender el cultivo del arroz ganando terreno a las marismas o para construir carreteras que conectasen mejor el turismo, la agricultura y la industria onubenses - recordemos que el llamado Polo (Químico) de Promoción y Desarrollo de Huelva se había aprobado en 1964 (Valverde, 2004). La creación del Parque ponía a Doñana bajo la tutela del Instituto para la Conservación de la Naturaleza (ICONA), establecido en 1970 dentro del cuerpo de ingenieros forestales y dependiente del Ministerio de Agricultura (García Álvarez, 2010).

Se esperaba que el ICONA estuviese mejor posicionado que el CSIC para defender los intereses del Parque frente a los planes desarrollistas. La figura jurídica del Parque Nacional fue en efecto útil en los años plagados de incertidumbres que siguieron y que han sido estudiados en diversos lugares. Aquí solo quiero señalar que en las polémicas sobre el desarrollo de las marismas que siguieron en las décadas de 1970 y 1980 cada parte aportaba sus propios datos y resultados desde diversas disciplinas científicas. Por ejemplo, el Ministerio de Agricultura insistía en que sus estudios hidrológicos y los de la Food and Agriculture Organization (FAO, ONU) demostraban la independencia freática de Doñana respecto de su entorno (Fernández y Pradas Regel, 2000). Aunque esto resultó ser falso, la incertidumbre en aquellos años era real y los propios estudios de la UICN realizados en los 50 y 60 habían desvinculado la salinización de Doñana de la construcción de diques ${ }^{14}$.

Esta misma incertidumbre acompañó a la polémica sobre pesticidas, pues la Federación Sindical de Agricultores Arroceros insistía en que no afectaban a las aguas del Parque ${ }^{15}$. Tras la publicación diez años atrás del libro de Rachel Carson, Silent Spring, los pesticidas se habían convertido en la bestia negra del ecologismo activista, y en especial de los protectores de aves. En 1973 y años posteriores, los picos excepcionales de mortandad de aves en Doñana se achacaban por unos a los pesticidas y por otros a sequías y otros factores. La posición del WWF al respecto era ambigua, entre otras cosas porque su primer y más importante donan- te corporativo era la empresa petroquímica Shell, que por entonces trataba de hacerse con una parte significativa del mercado mundial de pesticidas. Para agravar aún más la situación, la empresa familiar de Hoffmann fue responsable en 1976 del mayor accidente contaminante provocado por pesticidas en el norte de Italia, lo cual estuvo a punto de costar al suizo el puesto de vice-presidente del WWF (Schwarzenbach, 2011, pp. 145-151). En 1973 el WWF publicó un estudio realizado in situ por toxicólogos holandeses que, aunque admitía que había restos de DDT y otros pesticidas en el organismo de ciertas aves y sus huevos, concluía que los pesticidas eran una amenaza menor para el Coto, y mucho menos apremiante que la caza furtiva o el turismo (Hoorn y Boerwinkel, 1973).

En estos debates sobre las marismas y sus recursos, los factores económicos eran fundamentales, y la necesidad de aliviar la pobreza de un área tradicionalmente deprimida se consideraba urgente. Por ello, tanto el ICONA y Adena misma admitían a mediados de 1970 que el desarrollo de la zona era "necesario" y confiaban en que la figura jurídica del Parque Nacional permitiera retrasar y suavizar algunos de los proyectos de modo que fuese compatibles con la preservación de Doñana ${ }^{16}$. La desaceleración consiguiente a la crisis económica de 1973 y la creciente importancia del turismo fueron claves en cambiar la tendencia y dotar de fuerza real al Parque, pero para ello hubo de resolverse primero un conflicto interno entre dos modos de entender el conservacionismo.

En efecto, la creación del Parque Natural introdujo sus propios problemas, que han sido achacados por los propios implicados y por los historiadores a la bicefalia entre la Estación y el ICONA y las consiguientes luchas entre biólogos e ingenieros forestales, a menudo interpretadas como el enfrentamiento entre el interés por la naturaleza de los biólogos frente a los residuos productivistas de los forestales (Fernández y Pradas Regel, 2000). Sin embargo, se trataba también de un enfrentamiento entre dos modos de entender la conservación. Tanto Valverde como su discípulo y sustituto a partir de 1974, Javier Castroviejo, veían en Doñana una oportunidad para catapultar a la ecología española a las primeras filas internacionales mediante la producción de estudios doctorales, la invitación a investigadores extranjeros y la organización de congresos $^{17}$. Según Valverde, "Ios fines principales de la Estación son: desarrollo de investigación, conservación de la naturaleza y divulgación científica, por este orden de importancia." ${ }^{18}$ Por ello, los ingenieros forestales acusaban a los biólogos de tratar a Doñana 
como su cortijo, impidiendo o dificultando tanto las tareas del ICONA como las visitas de curiosos y poniendo en peligro la fauna y la flora con tal de avanzar en sus estudios universitarios. A estas críticas se unían los propietarios, los guardas y los cazadores locales, que aseguraban que el mantenimiento tradicional del Coto era necesario para su preservación (González Gordon, 2000; Gómez-Baggethum, Mingorría, ReyesGarcía, Calvet y Montes, 2009; Gómez-Baggethun, Reyes-García, Olsson y Montes, 2012).

Se trataba por tanto de dos modelos de conservación no del todo compatibles, el científico y el recreativo. Lo que quiero resaltar en lo que queda de esta sección es que la resolución de esta disputa vino en parte dictada por un cambio en el equilibrio de alianzas a favor del ICONA y que este cambio era a la vez un reflejo de y una contribución a la evolución de las ideas conservacionistas imperantes en el WWF.

Desde las expediciones de los 50 hasta mediados de los 70, los biólogos de la Estación habían sido los interlocutores únicos del WWF. Se recordará que Hoffmann y Nicholson favorecieron la creación de la Estación según el modelo de Tour du Valat orientado a la investigación científica. Sin embargo, a finales de la década de los 70 Nicholson aseguraba que "retrospectivamente, el énfasis en la importancia científica de Doñana no reconoció que...la salvación de una región tan extensa y parcelada depende de abrir partes de la misma y de sus tesoros naturales a las visitas a gran escala bajo la supervisión adecuada que asegure que las comunidades ecológicas no reciben daño mientras el área contribuye su parte a la economía de una de las regiones más pobres de España." ${ }^{19}$ Según Nicholson, ni Valverde ni Castroviejo captaron "la parte Parque Nacional del mensaje", la referida a los visitantes. En 1976, Hoffmann explicó a Nicholson que el WWF había empezado a dialogar con José Lara, director del ICONA, la autoridad legal del Parque y cuyos oficiales sí tenían interés en organizar la recepción de visitas $^{20}$. Poco después, Nicholson, nombrado por el WWF "árbitro" entre las diferentes partes en disputa, redactó un Master Plan dirigido a guiar al ICONA en la transformación de Doñana en un centro de recepción de visitas masivas ${ }^{21}$.

El interés de Hoffmann y Nicholson en fomentar el turismo de naturaleza no era totalmente nuevo, ya que en 1966 el International Biological Program había enviado a Herbert Axell, principal ayudante de Nicholson en el Nature Conservancy, para asesorar sobre la creación de lagunas, la construcción de observatorios y senderos, y la gestión de visitantes ${ }^{22}$. Aunque la ambigüedad hacia el turismo seguía siendo común entre los conservacionistas, en la pugna entre modelos de investigación y de recreación para Parques Naturales la hegemonía estadounidense favorecía el modelo recreativo (de Bont, 2011; Kupper, 2012; Rumore, 2012; Sutter, 2012; Tyrrell, 2012). Aún más importante, nuevas concepciones de la conservación y la ecología favorecían el énfasis en productividad económica. Como principal responsable del área de conservación del IBP, la mayor preocupación de Nicholson en aquellos años era la de hacer compatible el bienestar económico a escala planetaria con la conservación (Schleper, 2016; Lawrence, 2015). En crítica explícita a los postulados originales del $W W F$, Nicholson defendía ahora que la conservación solo funcionaría si era capaz de ir a la raíz de los problemas: "desarrollo, energía y crecimiento de la población" (Schwarzenbach, 2011, p. 164). Como se recoge en la contribución de Sarah Hamilton ${ }^{23}$ a este mismo número, distinciones parecidas entre un conservacionismo elitista de enfoque reducido y un ecologismo con vocación de ir más allá de determinados espacios y abarcar cuestiones sociales y modelos productivos se estaban dando en España en la misma época.

El enfoque de Nicholson iba acompañado de una concepción integral de la ecología en la que la cuestión central era la "capacidad de carga" del planeta en su conjunto y de una región en particular teniendo en cuenta las entradas de agua y minerales y la escala de la cadena trófica (lo que llamaba "productividad primaria"). La crítica organizativa a los biólogos de la Estación se convertía así en una crítica científica. La Estación había realizado estudios interesantes sobre determinadas especies e importantes censos de aves, estos últimos con ayuda de técnicos de Tour du Valat ${ }^{24}$. Pero, de acuerdo con Nicholson, los programas de investigación de la Estación habían despreciado el estudio integral del ecosistema, comprendiendo el agua y los suelos, a favor de intereses más parciales sobre comunidades tróficas, el tema predilecto de Valverde y continuado por Castroviejo ${ }^{25}$. Valverde figura como miembro del IBP y, desde 1970, del comité ejecutivo de la UICN. Sin embargo, su intento de incorporar la Estación como Centro Internacional del IBP fracasó. Aunque esto pudo deberse a falta de fondos, lo cierto es que el programa de investigación que presentó se fijaba solo en "productividad secundaria"26. Aunque Valverde ajustó su propuesta al vocabulario del IBP, Nicholson denunció en varias ocasiones que en la Estación no se desarrollaron trabajos ecológicos del tipo que interesaban al IBP integrando estudios de suelos, del régimen de agua y de productividad biológica vegetal ${ }^{27}$. 
El fomento de turismo en Doñana tenía una larga historia que iba desde el folclore de la romería del Rocío hasta la construcción de pisos de veraneo en las playas de Matalascañas, uno de los grandes peligros para la conservación del humedal (Ojeda Rivera, 1985, pp. 636-653). El turismo que promovía Nicholson era un tipo entre otros posibles: el de naturaleza. Cuando el ICONA aceptó el Master Plan y acondicionó el Parque para la recepción de visitantes, el WWF lanzó una campaña masiva internacional de fomento del turismo de naturaleza en Doñana ${ }^{28}$. Durante años, donantes del WWF que querían visitar el Parque habían protestado por las carencias de la Estación en la recepción de visitantes, y la campaña de promoción se dirigió especialmente a este grupo ${ }^{29}$.

La opción recreativa de Nicholson estaba pensada como una alternativa económica al desarrollo agroindustrial andaluz y al turismo de playa. El argumento económico ya había sido esgrimido por Huxley en la promoción de Parques Naturales en África con la que comenzábamos este artículo. Igual que entonces, el público en el que pensaba Nicholson para Doñana eran los naturalistas aficionados británicos. En un Ilamamiento a donantes británicos para Doñana en 1963, Nicholson aseguraba que "el 100\% del terreno estará en España, pero no sería raro que el 30 o 40\% de los visitantes sean británicos." Continuaba su argumento con una crítica al papel del turista inglés en el sur de España como origen de la especulación económica y la destrucción de la fauna y sus hábitats para concluir: "trajimos esto con nuestros dispendios económicos en España: solo contribuyendo con nuestro dinero podemos evitar el desastre para la fauna de España." ${ }^{\prime 30}$

\section{CONCLUSIÓN}

La conclusión de este artículo vuelve sobre la premisa metodológica expresada en su título: "la Naturaleza no existe". La frase va más allá de una mera provocación literaria e incluso de su sentido metodológico inicial para adquirir un sentido ontológico más fuerte. La historia de Doñana revela tres modos en los que la Naturaleza (con mayúscula) no existe; y no ya como punto de partida, sino ni tan siquiera como punto de llegada.

El primer modo es de carácter político: si una sociedad política estatal consiste primariamente en la apropiación de un territorio, los recursos naturales son objeto de la soberanía nacional: "tras lograr la apropiación de su porción de la superficie terrestre y sin ningún principio internacional que responsabilice a los Estados del cuidado de su propia biodiversidad, cada Estado puede, en principio, hacer con su parte de la biosfera lo que le venga en gana" (Adam, 2014, p. 3). Aunque el ave no lo sepa, las fronteras que cruza son tan reales como sus plumas. Y al sobrevolar estas fronteras es cuando aparece la necesidad de negociar su internacionalización, de definir una Naturaleza que vaya más allá de los territorios nacionales. El medio ambiente que rodea (Umwelt, environ, environment) a los grupos humanos no es originariamente global, sencillamente porque no existe la humanidad como sujeto histórico-político que pueda ser rodeado. Por tanto, la internacionalización de la naturaleza es un proceso, y no la situación originaria de partida (Avant, 2004; de Bont, 2015).

Varios autores han señalado que tanto la biosfera global interconectada como el "nosotros" global son construcciones históricas que han madurado en circunstancias muy precisas (Poole, 2008; Edwards, 2010; Latour, 2011). Estas construcciones, además, a menudo ocultan que la oposición entre el Hombre y la Naturaleza se resuelve en realidad en la de hombres contra hombres a través de diversas naturalezas (Bueno, 1993; Cronon, 1996). Así, la conservación de Doñana se enmarca en el establecimiento de instituciones internacionales durante la Guerra Fría, instituciones internacionales diseñadas para establecer un orden mundial postcolonial en lucha por el control de los recursos naturales. Cuando el Gobierno de Franco ofrecía el Parque como regalo a "la humanidad" conservacionista, en realidad se refería al occidente con el que había logrado alinearse como tabla de salvamento que permitió al régimen extenderse en el tiempo.

El segundo modo en que podemos afirmar que la $\mathrm{Na}-$ turaleza no existe tiene que ver con la naturaleza como objeto de conservación. Han existido y existen distintos conservacionismos, a veces opuestos entre sí, y cada uno de ellos acarrea una definición distinta de la naturaleza que se trata de proteger. Sin salir del ámbito de Doñana hemos visto contraponerse criterios estéticos, cinegéticos, políticos, económicos, zoológicos y ecológicos. Algunos de estos parámetros exigían apelar a una naturaleza salvaje, prístina y libre de la mano del hombre, incluso si para ello había que echar mano de las tecnologías más refinadas. Pero la construcción de un reino de la naturaleza opuesto a un reino de la cultura ha sido y es un arma de doble filo para el conservacionismo y en concreto para la instauración de los Parques Naturales de todo el mundo (McKibben, 1989; Bueno, 1996; Cronon, 1996; Benson, 2010; Dunlap, 2012). Para sortear algunos de esos peligros, el Master Plan redactado por Nicholson no presentó a la naturaleza como desligada del hombre sino definida precisamente en términos de “capacidad de carga” de población humana. 
Igualmente, en los conflictos entre modelos científicos y recreativos para la conservación de Doñana, los principales portavoces del CSIC y del ICONA invocaban a la Naturaleza para atacarse mutuamente. Y sin embargo la Naturaleza no fue el árbitro que señaló cuál de las dos opciones propuestas habría de seguirse, sino que el grupo vencedor fue aquel que logró reclutar más aliados. El esquema recuerda a la famosa simetría metodológica que pedían los sociólogos de la ciencia a la hora de analizar una controversia científica pasada: el historiador no debía suponer que la Naturaleza estaba desde el principio de lado de la parte victoriosa, sino que debía analizar las estrategias seguidas por ambos bandos para reclutar aliados tanto físicos como sociales (Latour, 1999). En el seno de una disciplina científica, el principio heurístico de la simetría tiene serias limitaciones, en especial cuando se pretende elevar a conclusión filosófica relativista (Alvargónzalez, 2013). Estas limitaciones no existen cuando se habla de la conservación de un territorio dado, puesto que, como hemos visto, en estos casos cada una de las diferentes disciplinas en pugna tiene los mismos títulos que las otras para reivindicar tener la verdad científica de su lado en lo que se refiere a la escala con la que mira o transforma ese territorio dado. Esto nos pone frente al tercer modo en que la naturaleza no existe: el pluralismo científico.

Por pluralismo científico me refiero al hecho de que diversas disciplinas configuran realidades a diferentes escalas y producen diferentes verdades en su seno. Tanto la teología de la omnisciencia como el positivismo moderno prometían la posibilidad de una ciencia que explicara todas las demás o las redujera, lo que el neopositivismo llamó la Ciencia Unificada, siguiendo el ideal de la mathesis universalis de Descartes o de Leibniz. A pesar de todos los intentos prácticos, científicos de diversas ramas se resisten a la subsunción de sus disciplinas en ciencias supuestamente originarias o fundamentales (Anderson, 1972). Varios historiadores y filósofos de la ciencia han descrito estos procesos de fracaso de reducciones gnoseológicas y han constatado cómo la realidad del pluralismo científico tiene consecuencias pluralistas ontológicas (Dupré, 1993; Galison y Stump, 1996; Cartwright, 1999). No falta quien proponga una supuesta unidad originaria monista que subyacería a los diferentes campos científicos, pero parece menos arriesgado tomar como punto de partida las secuencias de operaciones humanas de las que nos hablan la antropología cultural, la historia medioambiental y la historia de la ciencia. Según esto, la pluralidad de las ciencias se puede interpretar como un síntoma de la pluralidad ontológica de partida. Para decirlo en los términos de la Teoría del Cierre Categorial de Gustavo Bueno, existen tantas categorías ontológicas como ciencias, y sus respectivos campos son roturaciones técnicas y conceptuales de realidades que a veces podrán solaparse o reducirse pero otras veces serán independientes o incluso incompatibles (Bueno, 1991-1992). Cada una de estas ciencias, por tanto, tendrá algo diferente que decir del mismo territorio sin que exista un modelo que las unifique a todas y nos permita hablar en nombre de la Naturaleza. Hemos visto cómo diversas ciencias, e incluso corrientes distintas dentro de la ecología, aplicaban filtros distintos a la misma parcela de terreno, Doñana, y cómo la resolución de estas inconmensurabilidades había de venir desde fuera.

Esta conclusión no debe ser entendida como una llamada al cinismo ni como un desprecio escéptico por la conservación de Doñana o de otras naturalezas. Al fin y al cabo, quienes consideran a la Naturaleza como una cornucopia de productos ilimitados que se ofrecen a chorros llenos para el uso y disfrute de los hombres están imbuidos de la misma mitología monista de quienes, como Bernis, creen encontrar en la Doñana salvaje la Naturaleza con mayúscula. Como animales que somos, nuestra relación con el medio es básica en sentido biológico, pero también político, pues para vivir en ciudades, los animales sociales deben primero ocupar un territorio del que extraer sus energías, que no son inagotables sino que están expuestas a la acción depredadora de quienes se ceban en ellas. Por otro lado, los valores estéticos (y económicos) que se asignan hoy día a la contemplación del paisaje o a la captura fotográfica de aves siguen siendo elevados. Lo que el pluralismo científico y ontológico ofrece es la posibilidad de mejorar los esquemas, demasiado a menudo míticos, con los que nos acercamos como historiadores (pero también como científicos y como ciudadanos) a un problema tan central en las sociedades del presente como el de la conservación.

\section{AGRADECIMIENTOS}

La mayor parte de esta investigación fue financiada por el proyecto del Consejo Europeo de Investigación 241009, The Earth Under Surveillance, el projecto del MEC HAR 2014-57776-P, y por el Instituto Max Planck de Historia de la Ciencia. Agradezco a Carlos Tabernero y Santos Casado sus sugerencias, a Sarah Hamilton y Matthew Woodbury haberme proporcionado acceso a los papeles de Max Nicholson, y a Juan José Negro Balmaseda las facilidades que me dio para consultar los fondos de la Estación Biológica de Doñana. 


\section{NOTAS}

1. El conservacionista Jesus Garzón Heydt utilizó este argumento en más de una ocasión para atraer la atención internacional sobre Monfragüe: WWF. Urgent plea for help (25 noviembre 1977) (NP, c. 82).

2. Véase en este mismo volumen Santos Casado, Patrias primitivas. Discursos e imágenes de la naturaleza en el primer conservacionismo español.

3. El alejamiento entre la ornitología de los aficionados y la ornitología académica terminó de sellarse con tecnologías e investigaciones relacionadas con la guerra fría (MacLeod, 2001; Benson, 2010, pp. 5-51).

4. Nicholson. 1957 Spanish Expedition (NP, c.79)

5. Nicholson. Coto de Doñana. The Present State of Play (NP, c.87).

6. Nicholson. Coto de Doñana. The present state of play (borrador sin fecha) (NP, c. 87).

7. Nicholson a J. Castroviejo (9 marzo 1977) (NP, c. 82).

8. Para la continuidad de estas técnicas en las películas de Félix Rodríguez de la Fuente sobre Doñana, puede verse el artículo de Mònica Alcalá-Lorente y Carlos Tabernero en este mismo número.

9. Nicholson a Valverde (agosto 1957) (NP, c. 79).

10. Nicholson a Nylon (14 septiembre 1957) (NP, c. 80).

11. Nicholson. Draft (25 marzo 1963) (NP, c. 86).

12. Traducción libre de la Moción en la Segunda Cámara del Parlamento Sueco n. 306 (Estocolmo, 25 enero 1966) y del folleto Hinojos, een veilige vluchthaven voor vogelvrijen, Archivo de la Estación Biológica de Doñana, en adelante EBD, Hinojos-Aristrain, 1968-1970.

13. Carta de José Antonio Valverde a Luc Hoffmann (24 abril 1968). EBD, Adena; J. A. Valverde, Informe de actividades 1969 (Sevilla 15 enero 1970). EBD, Comité Directivo, resúmenes actividades 1963-1972.

14. S. H. Beaver a Fergusson-Lees (31 octubre 1957) (NP, c. 80); Nicholson. Doñana. History of a struggle (borrador 3 marzo 1978) (NP, c. 85).

15. Federación de Arroceros a Ministerio de Agricultura (sin fecha) (NP, c. 83)

\section{BIBLIOGRAFÍA}

Adam, R. (2014). Elephant Treaties, the colonial legacy of the biodiversity crisis. Hannover: University Press of New England.

Allen, D. (1976/1994). The Naturalist in Britain. A Social History. New Jersey: Princeton University Press.

Alvargonzález, D. (2013). Is the History of Science Essentially Whiggish? History of Science, 51 (170), pp. 85-99. http://dx.doi. org/10.1177/007327531305100104

Anderson, D. y Groves, R. (eds.). (1987). Conservation in Africa: People, Policies and Practice. Cambridge: Cambridge University Press.
16. Adena. Problemática del Parque Nacional de Doñana (sin fecha). EBD, Adena desde 1968.

17. Anteproyecto para el establecimiento de la Reserva y Estación Biológica de Doñana, 1963, EBD; J. A. Valverde a M. Lora Tamayo (13 abril 1970). EBD, Hinojos-Aristrain, 1968-1970.

18. J. A. Valverde. Resumen de actividades 1965-1966 (1 de mayo de 1966). EBD, Comité Directivo, resúmenes actividades 1963-1972.

19. Nicholson. The Rescue of Doñana (borrador sin fecha) (NP, c. 89); Nicholson. Doñana. History of a struggle (borrador 3 marzo 1978) (NP, c. 85).

20. Hoffmann a Nicholson (3 junio 1976) (NP, c. 82).

21. Nicholson. Master Plan. Draft (7 marzo 1977) (NP, c. 87 y c. 84).

22. H. Axell. Report on the Coto Doñana Biological Reserve, 18th March - 12 May 1966. EBD, Comité Directivo, resúmenes actividades 1963-1972.

23. Véase en este mismo volumen Sarah Hamilton, Activismo medioambiental en la época tardofranquista: el caso de El Saler.

24. J. A. Valverde. Informe sobre actividades en 1966 e Informe de actividades de 1971, EBD, Comité Directivo, resúmenes actividades 1963-1972.

25. J. A. Valverde a CSIC, Cuestionario laboratorios científicos en España (Sevilla, 27 noviembre 1965), EBD, División de Ciencias CSIC, 1965-1975; J. A. Valverde. Informe actividades 1970 e Informe de actividades 1971 y 1972, EBD, Comité Directivo, resúmenes actividades 1963-1972.

26. J. A. Valverde. Propuesta para incluir a la EBD como Estación Internacional de Campo para el Programa Biológico Internacional (Sevilla 14 marzo 1966). EBD, Comité Directivo, resúmenes actividades 1963-1972.

27. Nicholson a J. Castroviejo (9 marzo 1977) (NP, c. 82); Nicholson. Doñana. History of a struggle (borrador 3 marzo 1978) (NP, c. 85); Nicholson, M. Coto de Doñana. The Present State of Play (NP, c. 87).

28. Arthur Norman a José Luis Álvarez (4 diciembre 1981) (NP, c. 83); WWF, Promotion of specialist group visits to Doñana $\mathrm{Na}$ tional Park (diciembre 1981) (NP, c. 92).

29. Por ejemplo, Crawford H. Greenwalt a Castroviejo (12 junio 1978) (NP, c. 82).

30. Nicholson. Draft (25 marzo 1963) (NP, c. 86).

Anderson, P. W. (1972). More is Different. Science, 177 (4047), pp. 393-396. http://dx.doi.org/10.1126/science.177.4047.393

Avant, D. (2004). Conserving Nature in the State of Nature: The Politics of INGO Policy. Review of International Studies, 30 (3), pp. 361-382. http://dx.doi.org/10.1017/S0260210504006114

Barrow, M. V. (2011). On the Trail of the Ivory-Bill: Field Science, Local Knowledge, and the Struggle to Save Endangered Species. En: Vetter, J. (ed.). Knowing Global Environments. New Historical Perspectivs on the Field Sciences. New Brunswick: Rutgers University Press, pp. 135-161. 
Benson, E. (2010). Wired Wilderness. Technologies of Tracking and the Macking of Modern Wildlife. Baltimore: Johns Hopkins University Press.

Blackbourne, D. (2006). The Conquest of Nature: Water, Landscape and the Making of Modern Germany. Nueva York: W. W. Norton.

Boardman, R. (2006). The International Politics of Bird Conservation. Biodiversity, Regionalism and Global Governance. Cheltenham: Edwar Elgar.

Bressou, C. (1954). Actes de la Réserve de Camargue no 27: 19501953. La Terre et la Vie, 101 (1), pp. 3-16.

Brower, M. (2011). Developing Animals: Wildlife and Early American Photography. Minneapolis: University of Minnesota Press. http:// dx.doi.org/10.5749/minnesota/9780816654789.001.0001

Bueno, G. (1991-1992). Teoría del Cierre Categorial. Oviedo: Pentalfa.

Bueno, G. (1993). Pavores ecológicos. Ábaco, 2, pp. 12-31.

Bueno, G. (1996). El mito de la cultura. Ensayo de una filosofía materialista de la cultura. Barcelona: Prensa Ibérica.

Bueno, G. (2000). Televisión: Apariencia y Verdad. Barcelona: Gedisa.

Camprubí, L. (2014). Engineers and the Making of the Francoist Regime. Cambridge, Mass.: the MIT Press. http://dx.doi. org/10.7551/mitpress/9780262027175.001.0001

Cartwright, N. (1999). The Dappled World. A Study of the Boundaries of Science. Cambridge: Cambridge University Press. http:// dx.doi.org/10.1017/CB09781139167093

Casado, S. (2010). Naturaleza patria. Ciencia y sentimiento de la naturaleza en la España del regeneracionismo. Madrid: Marcial Pons.

Chapman, A. y Buck. W. (1893). Wild Spain: Records of Sport with Rifle, Rod and Gun, Natural History and Exploration. London: Gurney and Jackson. http://dx.doi.org/10.5962/bhl.title.54031

Cioc, M. (2009). The Game of Conservation: International Treaties to Protect the World's Migratory Animals. Athens: OH. http:// dx.doi.org/10.1353/book.7024

Cronon, W. (1996). The trouble with Wilderness; or, Getting Back to the Wrong Nature. Environmental History, 1(1), pp. 7-28. http:// dx.doi.org/10.2307/3985063

De Bont, R. (2011). Poetry and Precision: Johannes Thienemann, the Bird Observatory in Rossitten and Civic Ornithology, 19001930. Journal of the History of Biology, 44, pp. 171-203. http:// dx.doi.org/10.1007/s10739-009-9209-9

De Bont, R. (2015). R. Borderless Nature. Experts and the Internationalization of Nature Protection, 1890-1940. En Vanderdriesche, J., Peeters, E. y Wils, K. (eds.) Scientists' Expertise as Performance: Between State and Society, 1860-1960. Londres: Pickering and Chatto, pp. 49-65.

Deese, R. S. (2010). The New Ecology of Power: Julian and Aldous Huxley in the Cold War Era. En: McNeill, J. R. y Unger, C. R. (eds.). Environmental Histories of the Cold War. Cambridge: Cambridge University Press, pp. 279-300. http://dx.doi.org/10.1017/ cbo9780511730382.011

Delibes de Castro, M (2006). Aportación de la investigación y la ciencia a la construcción cultural de Doñana. En: Ojeda Rivera, J. F., González Faraco, J. C. y López Ontiveros, A. (eds.). Doñana en la cultura contemporánea. Madrid: Ministerio de Medio Ambiente, pp. 15-38).
Doel, R. E. (1997). Scientists as Policymakers, Advisors, and Intelligence Agents: Linking Contemporary Diplomatic History with the History of Contemporary Science. En: Söderqvist, T. (ed.). The Historiography of Contemporary Science. Amsterdam: Harwood Academic Publishers, pp. 216-244.

Dunaway, F. (2000). Hunting with the Camera: Nature Photography, Manliness, and Modern Memory, 1890-1930. Journal of American Studies, 34 (2), pp. 207-230. http://dx.doi.org/10.1017/ S0021875899006349

Dunlap, T. (2012). Beyond the Parks, beyond the Borders: Some of the Places to Take Tyrell's Perspective. Journal of American Studies, 46, pp. 31-36. http://dx.doi.org/10.1017/ S0021875811001447

Dupré, J. (1993). The Disorder of Things. Metaphysical Foundations of the Disunity of Science. Cambridge, Mass.: Harvard University Press.

Duque, A. (1977/2004). El mito de Doñana. Sevilla: Fundación José Manuel Lara.

Edwards, P. N. (2010). A Vast Machine. Computer Models, Climate Data, and the Politics of Global Warming. Cambridge, Mass.: the MIT Press.

Fernández, J. y Pradas Regel, R. (2000). Historia de los Parques Nacionales españoles (tomo IV). Madrid: Organismo Autónomo de los Parques Nacionales.

Fernández, J. (2004). 50 años en defensa de las aves, 1954-2004. Madrid: SEO/BirdLife.

Galison, P. y Stump, D. J. (1996). The Disunity of Science. Boundaries, Contexts, and Power. Stanford: Stanford University Press.

García Álvarez, A. (2010). Historia del Cuerpo de Ingenieros de Montes. Madrid: Colegio y Asociación de Ingenieros de Montes.

García Novo, F., Martín, A. y Toja, J. (2007). La frontera de Doñana. Sevilla: Universidad de Sevilla.

Garrido, H. (ed.). (2007). Doñana: diversidad y ciencia. Sevilla: Consejo Superior de Investigaciones Científicas.

Gissibl, B., Höhler, S. y Kupper, P. (eds.). (2012). Civilizing Nature. National Parks in Global Historical Perspective. New York: Berghahn Books.

Gómez-Baggethun, E., Mingorría, S., Reyes-García, V., Calvet, L. y Montes, C. (2009). Traditional Ecological Knowledge Trends in the Transition to a Market Economy: Empirical Study in the Doñana Natural Areas. Conservation Biology, 24 (3), pp. 721-729. http://dx.doi.org/10.1111/j.1523-1739.2009.01401.x

Gómez-Baggethun, E., Reyes-García, V., Olsson, P. y Montes, C. (2012). Traditional ecological knowledge and community resilience to environmental extremes: A case study in Doñana, SW Spain. Global Environmental Change, 22 (3), pp. 640-650. http://dx.doi.org/10.1016/j.gloenvcha.2012.02.005

González Arteaga, J. (2005). El arroz en las marismas del Guadalquivir: evolución y problemática actual. Sevilla: Universidad de Sevilla.

González Gordon, B. (2000). Una vida en Doñana: hechos, recuerdos y anécdotas de Antonio Chico, guarda mayor. Jeréz de la Frontera: Fundación González-Gordon. 
Hamblin, J. D. (2013). Arming Mother Nature. The Birth of Catastrophic Environmentalism. Oxford: Oxford University Press.

Harper, M. y White, R. (2012). How National were the First National Parks? Comparative Perspectives from the British Settler Societies. En: Gissibl, B., Höhler, S. y Kupper, P. (eds.). Civilizing Nature. National Parks in Global Historical Perspective. New York: Berghahn Books, pp. 50-67.

Hoffmann, L. (1958). An Ecological Sketch of the Camargue. British Birds, 51 (9), pp. 321-350.

Hoffmann, L. (1962). Station de Baguage de Camargue. La Terre et la Vie, 109 (1), pp. 34-77.

Höhler, S. (2007). The Law of Growth. How Ecology Accounted for World Population in the $20^{\text {th }}$ Century. Distinktion, 14, pp. 45-64. http://dx.doi.org/10.1080/1600910X.2007.9672938

Hoorn, A. J. W. y Boerwinkel, D. J. (1973). A Study on the Possible Side-Effects on the Fauna of the Coto-Donana in South-West Spain. Wageningen: Agricultural University.

Huxley, J. (1973). Memories II. New York: Harper \& Row.

Kupper, P. (2009). Science and the National Parks: A Transatlantic Perspective on the Interwar Years. Environmental History, 14 (1), pp. 58-81. http://dx.doi.org/10.1093/envhis/14.1.58

Kupper, P. (2012). Translating Yellowstone: Early European National Parks. Weltnaturschutz and the Swiss Model. En: Gissibl, B., Höhler, S. y Kupper, P. (eds.). (2012). Civilizing Nature. National Parks in Global Historical Perspective. New York: Berghahn Books, pp. 123-139.

Lambert, J. (1968). Conservation Year Proclaimed by Council of Europe. Science News, 93 (6), pp. 146.

Latour, B. (1999). For David Bloor...and Beyond: a Reply to David Bloor's Anti-Latour. Studies in History and Philosophy of Science, 30, pp. 113-129.

Latour, B. (2011). Waiting for Gaia. Composing the common world through arts and politics. A lecture at the French Institute, London, November 2011 for the launching of SPEAP (the Sciences Po program in arts \& politics. Disponible en http://www.brunolatour.fr/sites/default/files/124-GAIA-LONDON-SPEAP_0.pdf

Lawrence, A. (2015). A Member of the Food Chain? Quantifying Primary Productivity fron Nazi Germany to the International Biological Program, 1933-1974. [Tesis doctoral inédita]. University of California: Los Angeles.

López Ontiveros, A. (2006). La invención romántica y viajera de Doñana. En: Ojeda Rivera, J. F., González Faraco, C. y López Ontiveros, A. (eds.). Doñana en la cultura contemporánea. Ministerio de Medio Ambiente, pp. 39-92.

Macekura, S. (2011). The limits of the global community: the Nixon administration and global environmental politics. Cold War History, 11 (4), pp. 489-518. http://dx.doi.org/10.1080/14682745. 2010.498821

Mackenzie, J. M. (1988). The Empire of Nature: Hunting, Conservation and British Imperialism. Manchester: Manchester University Press.

MacLeod, R. (2001). Strictly for the Birds: Science, the Military and the Smithsonian's Pacific Ocean Biological Survey Program, 1963-1970. Journal for the History of Biology, 34, pp. 315-352. http://dx.doi.org/10.1023/A:1010371321083
Mazower, M. (2008). No Enchanted Palace. The End of Empire and the Ideological Origins of the United Nations. Princeton: Princeton University Press.

Matless, D. (1998). Landscape and Englishness. London: Reaktion Books.

McKibben, B. (1989). The End of Nature. New York: Random House.

Mels, T. (1999). Wild Landscapes: The Cultural Nature of Swedish National Parks. Lund: Lund University Press.

Mitchell, T. (2011). Carbon Democracy: Political Power in the Age of Oil. London: Verso.

Mitmann, G. (1999). Reel Nature: America's Romance with Wildlife on Film. Cambridge, Mass.: Harvard University Press.

Molina, J. (2011). Doñana: todo era nuevo y salvaje. Sevilla: Fundación José Manuel Lara.

Morenés y Mariátegui, C. (2005). Historia del Coto de Doñana, 1865-1985. Sevilla: Fundación Patrimonio Natural.

Moss, S. (2013). A Bird in the Bush: A Social History of Birdwatching. London: Aurum Press.

Mountfort, G. (1958/1994). Retrato de una tierra salvaje. Doñana: Patronato del Parque Nacional de Doñana.

Nicholson, M., Ferguson-Lees, J. y Hollom, P. (1957). The Camargue and the Coto Donana. British Birds, 50 (12), pp. 497-519.

Ojeda Rivera, J. F. (1985). Organización del territorio en Doñana y su entorno próximo. Siglos XVIII-XX. [Tesis doctoral inédita] Sevilla: Universidad de Sevilla.

Poole, R. (2008). Earthrise: How Man First Saw the Earth. New Haven: Yale University Press.

Rumore, G. (2012). Preservation for Science: The Ecological Society of America and the Campaign for Glacier Bay National Monument. Journal of the History of Biology, 45 (4), pp. 613-650. http://dx.doi.org/10.1007/s10739-011-9301-9

Ryan, J. R. (1997). Picturing Empire: Photography and the Visualization of the British Empire. Chicago: Chicago University Press.

Schleper, S. (2016). Conservation Compromises: The MAB and the Legacy of the International Biological Program, 19641974. Journal of the History of Biology, pp. 1-35. http://dx.doi. org/10.1007/s10739-015-9433-4

Schwarzenbach, A. (2011). Saving the World's Wildlife. WWF - The First 50 Years. London: WWF.

Sluga, G. (2010). UNESCO and the (One) World of Julian Huxley. Journal of World History, 21 (3), pp. 393-418. http://dx.doi. org/10.1353/jwh.2010.0016

Spence, M. D. (1999). Dispossesing the Wilderness: Indian Removal and the Making of the National Parks. Oxford: Oxford University Press.

Sutter, P. (2012). The Trouble with "America's National Parks": or, Going Back to the Wrong Historiography: A Response to lan Tyrrell. Journal of American Studies, 46 (1), pp. 23-29. http://dx.doi. org/10.1017/S0021875811001435

Tallon, G. (1954). La reserve naturelle de Camargue et le tourisme, La Terre et la Vie, 101 (1), pp. 111-117. 
Tilley, H. (2011). Africa as a Living Laboratory: Empire, Development, and the Problem of Scientific Knowledge, 1870-1950. Chicago: University of Chicago Press. http://dx.doi.org/10.7208/ chicago/9780226803487.001.0001

Turchetti, S. y Robers, P. (2014). The Surveillance Imperative. Geosciences during the Cold War and Beyond. New York: Palgrave MacMillan. http://dx.doi.org/10.1057/9781137438744

Tyrrell, I. (2012). America's National Parks: the Transnational Creation of National Space in the Progressive Era. Journal of American Studies, 46 (1), pp. 1-21. http://dx.doi.org/10.1017/ S0021875811001320

Valverde, J. A. (1958). An Ecological Sketch of the Coto Doñana. British Birds, 51 (1), pp. 1-23.

Valverde, J. A. (2003). Memorias de un biólogo heterodoxo (tomo II: En el Consejo Superior de Investigaciones Científicas). Madrid: V \& V /Quercus.
Valverde, J. A. (2004). Memorias de un biólogo heterodoxo (tomo IV. La aventura de Doñana. Cómo crear una reserva). Madrid: V \& V/Quercus.

Waters, K. y van Helden, A. (eds.). (1992). Julian Huxley. Biologist and Statesman of Science. Houston: Rice University Press.

Wöbse, A. K. (2010). 'The world after all was one': The International Environmental Network of UNESCO and IUPN, 1945-1950. Contemporary European History, 20 (3), 331-348. http://dx.doi. org/10.1017/S0960777311000348

Wöbse, A. K. (2012). Framing the Heritage of Mankind: National Parks on the International Agenda. En: Gissibl, B., Höhler, S. y Kupper, P. (eds.). (2012). Civilizing Nature. National Parks in Global Historical Perspective. New York: Berghahn Books, pp. 140-156. 